\section{LA DISTOPÍA DE}

\section{LAS RELACIONES}

\section{INTERPERSONALES}

\section{Verónica Felipe Aznar}

Doctorando

Programa cine, televisión y medios interactivos. Facultad de Ciencias de la Información. Universidad Rey Juan Carlos. Camino del Molino s/n, 28943 Fuenlabrada, Madrid (España) - Email: veronica felipe@hotmail.com

\section{Resumen}

Nada es real, pues nuestras experiencias no son reales sino meras reconstrucciones de la realidad generadas por nuestro cerebro. Vivimos en una virtualidad constante y, por ello, con la llegada de las nuevas tecnologías de la comunicación las relaciones interpersonales se trasladan al mundo virtual donde los usuarios crean su nueva forma de vida.

\section{Palabras clave}

Relaciones Interpersonales, Nuevas Tecnologías, Ciberespacio, Teledildónica, Cibersexo, Distopía, Internet, Realidad Virtual, Simulación,

Virtualidad, Biotecnología

Key Words

Interpersonal Relations, New Technologies, Cyberspace, Teledildonica, Cybersex, Dystopia, Internet, Virtual Reality, Simulation,

Virtuality, Biotecnology

\section{Abstract}

Nothing is real, since our experiences are not real but mere reconstructions of the reality generated by our brain. We live in a constant virtuality and for it, with the arrival of the new technologies of the communication the interpersonal relations move to the virtual world where the users create their new form of life. 


\section{Introducción}

El término comunicación puede ser definido como el intercambio de información entre seres vivos que requiere de un procesamiento cognitivo por parte de los participantes, un proceso de codificación/decodificación. "Sé que cuando la gente habla intercambian algo entre sí, y que por eso hablan unos con los otros" (Eric Berne). Los participantes ya no se limitan a transmitir información, sino que se establecen transacciones. Ambas partes obtienen algo con ello.

Por naturaleza, el ser humano necesita comunicar. Y esta comunicación se caracteriza por ser dinámica, inevitable, irreversible, bidireccional, verbal y no verbal. Se trata de una comunicación interpersonal en la que los sujetos son accesibles en el espacio/tiempo. Actualmente, la estructura social basada en la comunicación personal es obviada con el nacimiento de las nuevas tecnologías, que brindan mayor independencia al ampliar las capacidades sensoriales.

Por su parte, el ordenador personal es la herramienta que ha sustituido los acercamientos humanos en los lugares tradicionales -las calles principales, el vestíbulo de un sindicato, bares-, convirtiendo nuestro mundo en un mundo platónico. El mundo de las formas y las ideas de Platón. La presencia del ordenador nos virtualiza y hace posible lo inimaginable con la creación del ciberespacio. En este nuevo espacio las ideas han cobrado forma en un mundo donde los demás puedan verlas. Ya no se comparten experiencias cotidianas sino realidades, una existencia virtual modificada que simula la realidad material de cada usuario.

$$
\begin{aligned}
& \text { “...Me siento muy diferente cuando estoy } \\
& \text { conectada. } \\
& \text { Soy mucho más extrovertida, menos inhibi- } \\
& \text { da. Diría que me siento más como yo mis- } \\
& \text { ma... Me siento más como quien desearía } \\
& \text { ser. Sólo espero que cara a cara pueda en- } \\
& \text { contrar alguna forma de ser en algún mo- } \\
& \text { mento mi yo electrónico” (Sherry Turkle, } \\
& \text { 1997:227). }
\end{aligned}
$$

Por su parte, toda sociedad se compone de sus ciudadanos, en este caso, los hackers ${ }^{\text {ii }} y$ los hobbyist ${ }^{\text {iii }}$. La mayoría pertenecemos a los hobbyist en grados diferentes. Y, por otro lado, de locales. Los usuarios crean en el ciberespacio MUDs ${ }^{\text {iv }}$ (Plataformas de Múltiples Usuarios), una nueva forma de comunidad donde los usuarios son jugadores y creadores, no solo de texto sino de nuevos "yos" a través de la interacción social. No obstante, los usuarios ambicionan más y crean programas capaces de simular un ser humano, un "bot". El programa se presenta como persona y es capaz de mantener una conversación, incluso de flirtear con su interlocutor. Evolucionan y 
se convierten en “agentes”. Herramientas que administran la información y procesos de tu máquina. Llegan a construir su propia identidad, así como a confiar y mantener comunicación con los “agentes” de otras máquinas independientemente de su ubicación.

El ciberespacio se ha convertido en un territorio donde jugar a la simulación se convierte en parte de la vida real.

"Es un escape total... En IRC soy muy popular. Tengo tres personalidades que utilizo un montón...De manera que uno se toma en serio la guerra de Yugoslavia, otro está un poco chiflado por Melrose Place y un tercero lleva mucha actividad en los canales sexuales, siempre buscando pasar un buen rato...Quizás sólo puedo relajarme si veo la vida como un canal IRC más" (Sherry Turkle, 1996:228).

Estos usuarios adictos al mundo que les ofrece el ciberespacio se introducen en un bucle de aislamiento $^{\text {vi }}$ de la realidad y disminución del círculo social.
Los MUDs difuminan las fronteras entre el yo y el rol. "Eres lo que pretendes ser...eres lo que juegas a ser". El anonimato, la falta de factores que inhiben al usuario, la protección dada por la separación física de los terminales y la distancia geográfica hacen más atractivo, si puede, la inmersión a la nueva tecnología virtual.

Las interacciones habituales tenidas hasta ahora en los MUDs evolucionan. El ordenador ya no es el intermediario entre nuestras comunicaciones interpersonales. La frialdad generada en ellas se difumina al implantar en nuestros cuerpos chips electrónicos. Nuestros cuerpos van sufriendo una transformación tecnológica sin perder su biología por completo. Recuperamos el contacto humano en cuanto a la cercanía de los cuerpos, pero el anhelo de los usuarios es conseguir simular el mundo que conocemos y vivir en él con nuestras copias. Nuestra única existencia biológica será la mente.

El futuro que anhelamos. La vida eterna.

\section{Objetivos}

Mostrar el cambio en las relaciones interpersonales generado por la llegada de las nuevas tecnologías y como los mundos creados en las novelas de principios del siglo XIX están respaldadas por los avances científicos y tecnológicos actuales mostrándose dichos posibles mundos en el cine. 


\section{Metodología}

Se toma como referencia las teorías de la comunicación y estudios relacionados con las relaciones interpersonales para llevar a cabo una relación de evolución con la aparición de las nuevas tecnologías y el cambio que éstas generan en el comportamiento social de los usuarios. Para mostrar dichas evoluciones hacemos uso de diferentes largometrajes que toman como objeto principal o secundario de su historia un elemento tecnológico, el ordenador y sus diversas evoluciones tecnológicas.

\section{Establecer contacto ${ }^{\text {vii }}$}

El ser humano es un ser socializador que necesita comunicar. La rapidez con la que la sociedad se mueve en estos días conduce a que la mayor parte de su tiempo lo pase solo en la pantalla de un ordenador o de un televisor.

Durante todo su ciclo vital, el ser humano se ve obligado a asumir roles y máscaras sociales. Pero esto requiere un estricto control que, en ocasiones, resulta irritante. Por ello, existen roles marginales que forman en sí una forma de vida.

"En las sociedades tribales, el merodear del chamán podría implicar estar poseído por los dioses y los espíritus. En los tiempos modernos, existió el artista del timo, el bígamo...Ahora en los tiempo posmodernos, las identidades múltiples ya no están en los márgenes de las cosas...experimentan con la identidad como un conjunto de roles que se pueden mezclar y combinar, cuyas demandas diversas necesitan ser negociadas". Por eso, "Internet se ha convertido en un significativo laboratorio social para la experimentación con las construcciones y reconstrucciones del yo que caracterizan la vida posmoderna". (Sherry Turkle, 1997).

La combinación ofrecida por la sociedad e Internet -rapidez/experimentación- llevan a que el usuario se "autocree" en un mundo paralelo. Su nuevo espacio vital. Primero, el usuario sustituye su realidad por la virtualidad. Su círculo social va desplazándose progresivamente a un mundo no corpóreo. Segundo, las relaciones que se crean en estos chats se hacen más intensas que las relaciones tradicionales en menos tiempo porque los usuarios están aislados en un mundo remoto, poco familiar y con sus propias reglas. En Tienes un e-mail, dos rivales, Kathleen Nelly - propietaria de una pequeña librería- y Joe Fox -propietario de una cadena de grandes librerías- no son compatibles en el mundo real/corpóreo. La soledad de ambos personajes hará que usen el mismo servicio de Internet y coincidan en él. El deseo de encontrar compañía hará que una comunicación transmitida 
por vía fría ${ }^{\text {viii }}$ se convierta en aquello que uno anhela: deseo, pasión, amor... esperanza. Asimismo, Otros días vendrán, Buscando un beso a medianoche y Tapas reflejan situaciones similares. Usuarios que se conectan a chats en busca de una relación y que su intensidad lleva al contacto físico en el mundo real. Pero, en ocasiones, el objetivo de ambos no converge, un usuario puede estar preparado para tener una relación en lo virtual, pero no en la vida real. Como ya se mencionó, el ordenador modifica la personalidad del usuario considerablemente aislándolo de la realidad y obviando el tiempo y el espacio.

Tercero. No solo se intenta buscar una relación sentimental. También la evasión es posible. En The holiday, Amanda e Iris deciden intercambiar ambos mundos: Brentwood, Los Ángeles/ Rose Hill Cottage, Inglaterra para dar comienzo a una nueva vida.

Sin embargo, no todo es evasión. Experimentar a ser un hombre/mujer es atractivo, más aún si es con un fin lúdico. Como bien hacía ver Shakespeare en sus obras, el mundo es un escenario donde cada uno de nosotros es un actor interpretando un papel...o muchos. Internet facilita el cambio de género, la experimentación al servicio del usuario, pero no exenta de posibles engaños. En Closer vemos como Larry está siendo víctima de un engaño. Un personaje en el divertimento de Dan.
El segundo escalón a esta osadía es la violación en Internet. La virtualización del medio permite manipular datos y usuarios. En Copycat la profesora Helen Hudson es acosada por un hacker que escenifica los asesinatos relatados en sus novelas. Además, encontramos la violación "justificada" por Hayley (Hard Candy) quien asume la misión de castigar a Jeff, fotógrafo que se dedica a captar por chats a menores para fotografiarlas. Hayley hará uso de las posibilidades que ofrece Internet -el anonimato para llegar a su objetivo. Lisbeth Salander, Millennium 1: Los hombres que no amaban a las mujeres, accede a los archivos privados de Mikael Blomkist que le introducirá en una trama de asesinatos y desapariciones protagonizadas por nazis. La violación de códigos - el acceso a los archivos secretos- será el nexo de unión.

La atracción generada por la pantalla está motivada por la curiosidad de conocer donde están los límites a la intromisión y por la falta de autoestima de los usuarios. Expectativas vitales inalcanzables que inducen a una depresión anunciada y a la búsqueda de un espacio donde proyectar personajes alternos -desdoblan su personalidad para poder optar así a sus expectativas-.

Los usuarios conservan cierta distancia entre la combinación hombre-máquina. Pero el avance tecnológico y el anhelo de los usuarios por amplificar más sus capacidades llevarán a que cedan a la pérdida de 
ciertos aspectos biológicos para devenir en

\section{2. Éxtasis o LSD electrónico (RV)}

La teledildónica ${ }^{\mathrm{ix}}$ es, coloquialmente, sexo virtual. Un servicio entre dos o más personas donde describen a través de texto acciones y reacciones físicas para la estimulación sexual. Esta actividad se ha convertido en una pieza central de la experiencia para muchos usuarios.

Al principio fueron los MUDs, donde las situaciones se aceleraban. Conversaciones inocentes que se convierten en relaciones inesperadas. En los largometrajes Tapas, Buscando un beso a medianoche y Otros días vendrán los diferentes protagonistas utilizan los chatrooms y las redes sociales para entablar conversaciones íntimas. El efecto de la simulación visible entre los dígitos, pues lo artificial es más persuasivo que la realidad; las relaciones íntimas son más profundas que las reales; la falsa sensación de haber conseguido más de lo que pensamos y ver que nuestra experiencia de lo real es sesgada por la virtualidad.

Por su parte, Howard Rheingold plantea que esta tecnología es solo un experimento mental (gedankenexperiment) que trata de inducir a las personas a una postura mental apropiada para advertir las implicaciones del nuevo descubrimiento. Sin embargo, participó inconscientemente en este experimento escribiendo una improvisación en entes del espacio digital.

el ciberespacio que generó gran trascendencia concluyendo que

"cuando la gente parece querer que se desarrolle una tecnología, anhelar literalmente disponer de un nuevo juguete posible, esa necesidad puede adoptar una fuerza propia, sobre todo dada la velocidad del progreso en las tecnologías habilitantes y las enormes fuerzas impulsadas por el mercado que quedarán liberadas cuando el sexo a distancia se vuelva posible". (Howard Rheingold, 2002:363)

Asimismo, la interactividad que permite esta tecnología es sumamente atractiva para el usuario, le sumerge en una inmersión al límite de la adicción ya que

"la atracción de las drogas alucinógenas es un medio para alcanzar empatía con nuestro ambiente eléctrico penetrante, un ambiente que en sí mismo es una excursión interna sin drogas". (Marshall McLuhan, citado en Rheingold, 2002:367).

Asimismo, permite experimentar encuentros eróticos asépticos y con una profunda carga emocional. Además, conduce a un aislamiento sin precedentes. Nos ubicamos en cubículos aislados, donde estamos hipnotizados por nuestros propios medios gracias a la adicción de esta nueva droga conocida por algunos como LSD electróni- 
co y que afecta a nuestras percepciones humanas.

Por otro lado, el hombre nació para crear herramientas que generaran otras herramientas y la teledildónica se ha convertido en un amplificador de la capacidad humana. Como dice Pierre Lévy, "la virtualización es el movimiento por el cual se ha construido $y$ continúa creándose nuestra especie". Conforme va aumentando la expectativa del sexo virtual, los usuarios esperan impacientes la aparición de sistemas que permitan la representación de sensaciones hápticas ${ }^{\mathrm{x}}$. William Gibson definía este sistema como "la percepción del individuo adyacente a su cuerpo mediante el uso de su propio cuerpo".

Para su logro, primero se empezó con los guantes sensitivos: DataGlove ${ }^{\mathrm{xi}}$, CyberGlove, PowerGlove de Mattel, DHM ${ }^{\mathrm{xi}}$. Segundo, los cascos de visualización que permitieron ampliar el campo de visión del usuario. En El cortador de césped vemos como gracias a esta tecnología el Dr. Lawrence Angelo consigue incrementar la capacidad intelectual de Jobe, deficiente mental. Por su parte, Jobe utiliza el manejo de la máquina y sus conocimientos como elemento dominante sobre su pareja para hacerla sucumbir a sus deseos más perversos. Los cuerpos responden en este universo a texturas gelatinosas fundiéndose en el ciberespacio con un gran espectro de colores. Presenciamos la primera violación cibernética. Asimismo, el uso descontrolado (adictivo) de esta tecnología invita a la pérdida de la razón. Jobe se ha convertido en un sistema informático, ha trascendido lo biológico.

Gracias a la imaginación humana hemos superado la comunicación vía texto y podemos disponer de tecnología que nos permita tener sexo virtual aún no estando en la misma habitación, incluso estando en continentes diferentes. Imagínese que

"conecta todo su sistema de telepresencia de sonido, vista, tacto en una red telefónica. Usted ve una representación visual verosímil, pero totalmente artificial, de su propio cuerpo y del de su pareja...Su(s) pareja(s) pue$\mathrm{de}(\mathrm{n})$ moverse independientemente en el ciberespacio y sus representaciones son capaces de tocarse mutuamente, aun cuando los cuerpos físicos sean continentes separados... Usted pasa la mano sobre la clavícula de su pareja, y a nueve mil kilómetros de allí, se disparan una serie de efectores, en el orden correspondiente, a la frecuencia adecuada, para transmitir el contacto justo en la forma en que usted desea que sea transmitido. Si a usted no le gusta cómo se desarrolla el encuentro, o alguien requiere su presencia en la realidad física, puede desconectar todo moviendo un conmutador o quitándose su traje virtual" (Howard Rheingold, 1996:360).

Esta fantasía es posible gracias al ingeniero Danilo De Rossi (Universidad de Pisa). De

Rossi creó una piel artificial inteligente hecha de gel que se encontraba entre dos capas de electrodos que controlaban el flujo de electricidad a través del medio húmedo. Además, cuenta con una estruc- 
tura de sensores que emiten una carga eléctrica cuando se someten a presión. Por otro lado, los militares también se introdujeron en la misión de amplificar la fuerza de sus soldados a través de aumentar su resistencia. La estructura del JEDI ${ }^{\mathrm{xiii}}$ que es un traje amplificador y/o retorno de esfuerzo y consiste en una estructura que contiene activadores de globitos de plástico y de caucho.

Un ejemplo fílmico de este imaginario lo encontramos en Tomás está enamorado donde todos los servicios se han trasladado al ciberespacio, incluido los servicios sexuales. Tomás se ha encerrado en su habitáculo personal bien equipado tecnológicamente. En un principio, sus relaciones se limitan a conversaciones a través de videollamadas y chatrooms. La limitación e insatisfacción de su universo le lleva a probar los servicios sexuales profesionales on-line. Descubre las aplicaciones del traje cibernético con múltiples sensores que permiten percibir las superficies y las sensaciones táctiles. Estos se colocan en las partes del cuerpo que se deseen para su posterior estimulación. Sexo a la carta.
En el mundo de la teledildónica cada uno ve lo que anhela ver, pero la experiencia sexual real da más información. En ella, percibes el calor, la complicidad y la empatía de la otra persona. Aspectos imperceptibles en los registros cibernéticos de las diferentes relaciones virtuales que puedes llegar a tener. Esta fantasía tiene el inconveniente de que no se han desarrollado ordenadores capaces de ejecutar tal cantidad de cálculos para poder controlar los miles de sensores y efectores que requiere.

Sin embargo, Memo y Luz nos muestran cómo es posible. La fusión de ambas prácticas sexuales: cibernética y biológica. En Sleep Dealer los protagonistas tienen en sus cuerpos una serie de nodos que les permiten conectarse a máquinas $\mathrm{y}$, también, entre ellos para experimentar y verse por dentro. El sexo que ellos experimentan es la visualización de sus recuerdos acompañado del contacto físico en el mundo real. Tienen una relación que comprende dos mundos, una doble sensación, un doble éxtasis sexual.

\section{El atractivo del bit}

Las acciones realizadas en la navegación por Internet quedan registradas en varios servidores durante un periodo de tiempo. Toda esa información es accesible a los usuarios más aventajados en dominio informático. Por ello, la intimidad y la seguridad son meras sensaciones. Como bien comenta un usuario ya no hay libertad, pues nosotros mismos la coartamos,

“me suscribí... y escribía cada día. Era una liberación. Mis ideas eran bastante salvajes. 
Después descubrí que la lista se archivaba en tres lugares. El correo electrónico te hace sentir como si solo estuvieses hablando. Se evaporará como el habla. Y entonces lo que dices se archiva, no se evapora. Es como si siempre hubiese alguien preparado para grabarte de forma permanente. Aprendes a vigilarte a ti mismo”. (Sherry Turkle, 1997:312)

Actualmente, no es primordial controlar toda la información, sino los accesos a la misma. Como dice Timothy Leary "la realidad virtual no tiene límites. De lo que se trata es del acceso a la información”. Se trata de un nuevo espacio con código abierto donde todos pueden ampliarlo, reducirlo y manipularlo. Estas posibilidades generan las continuas guerras digitales.

El hombre ambiciona y su codicia lleva a la creación de programas y/o virus que le permitan controlar a toda una sociedad, reducirla a meros "bits". "O eres un cero o eres un uno. Vives o mueres" (Conspiración en la red). El control de los bits es el futuro. Nicholas Negroponte en su libro El mundo digital habla de los átomos y los bits (lo material y lo inmaterial). El control de los átomos es sustituido por el de los bits porque abarca más usuarios y es infinito.

Leonardo, SINAPSE, Pre-Crimen, Nube, Skynet son algunos de los programas que podemos encontrar en la ciencia ficción y que muestran las posibilidades del nuevo mundo digital. El control de los usuarios. El dominio de la sociedad local, nacional y/o mundial.
El programa Leonardo (Hackers, piratas informáticos) encargado de destruir el sistema establecido e introducir el pánico en la sociedad y que inicia una guerra entre dos hackers. Por su parte, Milo (Conspiración en la red), tendrá que hacer frente al SINAPSE. Programa creado por Gary Winston gracias al robo violento a hackers juveniles. Se le pude considerar como un lamer ${ }^{\text {xiv }}$ ya que se jacta a lo largo de todo el film de unos conocimientos que no son suyos, sino robados. Se trata de un sistema de comunicación vía satélite con acceso a todas las pantallas.

Asimismo, esta tecnología que debería estar al servicio de los usuarios y utilizarse para mejorar el funcionamiento de la administración y sus relaciones con el ciudadano, se aleja de su función social para destruir una sociedad o como advierte Grigori Burdea y Philippe Coiffet (1996:274) para controlar la sociedad, “también presenta grandes riesgos de disfunción: acciones y decisiones judiciales desafortunadas $y$ precipitadas, contenciosos, invasión de la vida privada, etc. Permitirá a las autoridades jugar al "Hermano Mayor", algo muy peligroso". En La red y Enemigo público vemos claros ejemplos de esta superioridad. Ángela Bennett, La red, recibe un virus que permite acceder a las bases de datos estatales. Descubre que todos los ordenadores están protegidos por el programa Nube -creado con anomalías para poder manipular los datos de cualquier ciudadano-. Caso similar ocurre con Robert Clayton Dean, protagonista de 
Enemigo público, se ve obligado a huir de la sociedad civilizada e introducirse en los submundos, pero Reynolds representa el "Gran hermano"x", el ojo que todo lo ve. Ambos protagonistas sufren una violación de identidad y son vigilados por un ente omnipresente. Hay que añadir el Skynet de Terminador 3: la rebelión de las máquinas. Un potente software/virus que manipula el interior de la máquina provocando un cambio en su programación. Su misión es acabar con la especie humana.

Llegamos al 2054 (Minority Report) donde el Departamento de Justicia desarrolla el programa Pre-Crimen que permite predecir el futuro y evitar así posibles delitos. La creación de una distopía donde un ordenador táctil, dependiente de las visiones de tres Pre-Cogs, rige el funcionamiento de una sociedad. Sociedad que cede ante el control tecnológico por mejorar la seguridad ciudadana.

Además de crear programas para el control mundial y mantener la seguridad, existen casos que responden al mito de Frankenstein. Por un lado, Víctor Taransky (Simone) crea su actriz ideal (un software) que le lleve al éxito cinematográfico como director. Pero el éxito excede de sus expectativas al adquirir Simone más protagonismo y relevancia social que él. Finalmente, elimina el software y vuelve a su anónima vida.

Por otro lado, La mujer explosiva muestra a dos adolescentes creando un collage femenino con recortes fotográficos en el ordenador. Una carga eléctrica hará que la chica imaginada cobre vida en el mundo real.

\section{La simulación ${ }^{\mathrm{xvi}}$}

La realidad virtual permite la creación de mundos virtuales - entornos artificiales semejantes a la vida real- donde el hombre interactúa con la máquina. Se trata de

"una tecnología de visualización y control que puede rodear a una persona con un ambiente virtual interactivo generado o mediado por el ordenador. Mediante dispositivos de visualización montados sobre la cabeza y que siguen sus movimientos, y otros dispositivos que registran los gestos y sonido en 3-D, se crea un mundo artificial de experiencia visual y auditiva...se crea un lugar artificial que puede ser explorado y que con- tiene objetos virtuales que pueden ser manipulados". (Michael W. McGreevy citado en Michael M.A. Miradito, 1998:402)

Al principio la tecnología de realidad virtual solo era practicable en los videojuegos que, por su coste, solo podían encontrarse en galerías comerciales o en ferias informáticas donde se daban a conocer. Ejemplo de ello es el caso de Justine (Sexualidad virtual). Justine es invitada a probar un cockpit de simulación. En él puede crear a su chico ideal con un casco de visualización y sensores en la mano para manipular los objetos de la pantalla. No obstante, esta 
tecnología presenta vulnerabilidades con el cableado eléctrico ya que los cascos de visualización $\mathrm{CRT}^{\mathrm{x} \text { xii }}$ requieren alta tensión y se localizan en la cabeza del usuario. Además, comprobamos las posibles consecuencias de su errónea ubicación, un cortocircuito exterioriza la realidad virtual de Justine. Caso opuesto el localizado en Tron. La realidad virtual captura al humano. El CCP (Control Central de Procesos) ha adquirido más poder para evitar así la intrusión de programadores humanos y tener controlados todos los programas. Éstos tienen vida propia y personalidad, los más avanzados evolucionan en el campo emocional. El usuario forma parte de la realidad virtual como también sucede en El cortador de césped.

Por su parte, Orson Scott Card, en su novela El juego de Ender, narra una historia similar. El adiestramiento de un equipo altamente cualificado para el manejo de armas modernas contra una civilización que amenaza con su existencia a través de un videojuego. Pero en un ejercicio de entrenamiento, las armas simuladas en el otro extremo son cambiadas en secreto por armas reales. Por ello, el problema radica en si se podrá prevenir que todas estas tecnologías se utilicen contra la humanidad así como la dificultad de distinguir el objetivo de las mismas, pues un convoy que entra en un edificio puede ser tanto para salvar vidas como para terminar con ellas. Asimismo, podemos relacionar este adiestramiento con el desarrollado en el video- juego "Battle Tech". Presenta una guerra futurista librada por robots y controlados por seres humanos. Los jugadores primero se familiarizan con la simulación, luego continúan por el área de preparación donde se conocen todos los participantes y, posteriormente, inician el juego. (Grigori Burdea y Philippe Coiffet, 1996:303).

Todo ello conduce a la posible situación de naves militares manejadas desde una silla en un cubículo y a los robots dirigidos por los humanos desde la otra parte de la frontera. Sleep Dealer muestra como las acciones controladas por control remoto cobran vida en el mundo real. Los humanos están conectados a un sistema digital a través de 'nodos'.

Por su parte, en Juegos de guerra se ha creado la máquina WOPR (War Operation Plan Response). Una máquina con inteligencia artificial que programa numerosas estrategias y juegos de guerra, entre ellos Guerra Termonuclear, para predecir los resultados de una posible guerra nuclear y poder responder a un ataque inminente. Una inteligencia artificial que evoluciona al tomar decisiones propias: traspasar la barrera de virtual/real provocando la posible Tercera Guerra Mundial entre Rusia y EE.UU.

Asimismo, todo avance tecnológico se caracteriza por tener aspectos positivos y aspectos negativos. Esta dualidad no apacigua el anhelo del ser humano de ir más allá de sus limitaciones, aunque con ello cambie $\mathrm{su}$ base biológica. "Imagínese que pudiera 
hacer copias de seguridad de su mente, que pudiera intercambiar experiencias con otras personas. Acceder instantáneamente a toda la información y experimentar realidad virtual de inmersión total". Hoy solo es posible en la ciencia-ficción, pero los avances tecnológi$\cos$ evolucionan progresivamente. Vayamos a Los sustitutos donde rudimentariamente podemos visualizar el prototipo de lo que se avecina. Robots formados por una copia exacta de nuestra mente -nuestros recuerdos y experiencias-, que nosotros controlamos desde nuestra casa y que cuando la desconectamos deja de funcionar. Por ello, la evolución hará posible la creación de un cuerpo virtual capaz de sentir lo mismo que un cuerpo biológico porque "cada experiencia o pensamiento, por pequeño que sea, lleva consigo un cambio neuronal. Una vez descubierto el procedimiento de estas modificaciones se genera un software que permite imitar el cerebro biológico. El cuerpo no será el mismo, pero continuará el patrón de

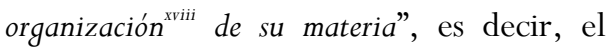
cuerpo estará habitado por una copia de nuestra mente. Asimismo, Xchange posibilita el cambio de patrón de organización entre seres biológicos. Cambias de cuerpo para poder teletransportarte, pero mantienes tu organización. En este caso no realizas copias, sino que intercambias patrones.

Por ello, llegará el día que no será posible diferenciar el ser tecnológico del ser biológico. A día de hoy es posible implantar chips en los seres biológicos para corregir sus limitaciones. Implantes cerebrales para recuperar la audición; prótesis para conservar la estructura corporal y el movimiento original; chips en gafas para representar la realidad en blanco y negro a los invidentes y se está estudiando el implantar nanorobots dentro del organismo. Su tamaño será como un glóbulo rojo y su misión, entre otras, será reprogramar nuestros genes para evitar enfermedades. Podrán interactuar entre ellos y con nuestras neuronas biológicas. Se establecerá una relación en el interior mismo del cuerpo biológico. El humano habrá asimilado en sí mismo el papel del ordenador.

En el filme Johnny Mnemonic observamos parte de estos avances donde los humanos se implantan chips de silicona para almacenar y transportar memoria. Su estatus radica en la capacidad de almacenamiento. Por otro lado, el auge de los implantes y la asunción de una nueva biología genética (la manipulada genéticamente) da lugar a la distopía representada en Un mundo feliz de Aldoux Huxley. Una tecnología reproductiva crea una humanidad permanentemente feliz a costa de la familia, la diversidad cultural, las artes, la ciencia, la literatura, la religión y la filosofía. Una sociedad próspera y saludable donde no existe ni la guerra ni la pobreza. Un mundo representado en Gatacca. Un mundo transhumanis$\mathrm{ta}^{\mathrm{xix}}$. Gracias a la tecnología, los hijos son creados "in vitro" y con dispositivos de selección genética. En un mundo totalmente artificial se hace necesario el uso de un ordenador para establecer la relación entre 
sus ciudadanos. La clasificación social entre los "no válidos" - hijos biológicos- y los "válidos" - manipulados genéticamente-

El deseo humano de la vida eterna se ve alcanzado parcialmente. Pues habitan un espacio originariamente biológico y la posibilidad del resurgimiento de seres biológicos. Así pues, el siguiente paso es la creación de un mundo virtual donde todos los usuarios partan de la misma base: los bits (los dígitos). The Matrix es la representación ficticia de este mundo simulado y responde a las palabras de Brenda Laurel de que

"la realidad siempre ha sido demasiado pequeña para la imaginación humana. El impulso de crear una máquina de fantasía interactiva sólo es la manifestación más reciente de un deseo antiquísimo de hacer que nuestras fantasías sean palpables" (Howard Rheingold, 1996:406).

El mundo virtual presentado en Matrix permite conectarse a todos los humanos a través de nodos. Una simulación de inmersión total donde todo es digital. La simulación tiene independencia y libertad. Crea programas con vida y personalidad propia. Los usuarios son en sí mismos programas que evolucionan y transforman su naturaleza, como es el caso de Smith que acaba convirtiéndose en un virus. Toda máquina es objeto de manipulación, pues se componen de códigos numéricos manipulables.

El anhelo de inmortalidad y extrema seguridad desvanecen cuando la existencia de un ser ya sea tecnológico o biológico depende del control de una máquina a la que todos los usuarios tienen acceso.

\section{Conclusiones}

Las nuevas tecnologías han desarrollado un nuevo ser humano que pasa gran parte de su vida en los mundos virtuales del ciberespacio y que es capaz de interactuar simultáneamente en mundos paralelos y cambiar de personalidad para adecuarse a los mismos. Esto ha generado un déficit de atención en los usuarios pues su paso por los diferentes portales de su mundo virtual es superficial. No se centran en ahondar en los entes u objetos con los que se encuentran sino que cuando no responden a sus peticiones en forma y manera desconectan.
No admiten réplicas. Además de generar problemas en la creación de identidades. La identidad de cada uno requiere del reconocimiento de un segundo. La interacción que estos usuarios ejercen en el ciberespacio no está centrada en el conocimiento profundo del interlocutor sino en intereses superficiales y materiales. La superficialidad de las interacciones lleva a una pérdida de identidad.

De esta forma, las posibilidades de las nuevas tecnologías facilitan una ilimitada conectividad en la interacción entre personas 
y el comenzar una nueva realidad con un nuevo rol social. Pero se ve confrontada por la creciente creación de fronteras físicas entre los seres humanos, la pérdida de la noción de realidad y del espacio/tiempo. El distanciamiento entre los seres humanos va en aumento mientras que en el ciberespacio hay una tendencia invertida. Asimismo, los mismos usuarios se distancian de su entorno social físico para acercarse más sentimental y profesionalmente a cibernautas. La incapacidad resolutiva y la falta de espontaneidad ante situaciones embarazosas caracterizan a nuestros usuarios incapaces de ver el advenimiento de la realidad futura. El aislamiento social deviene en la ciberhiper-socialización.

Asimismo, la creación de tecnologías que amplifican nuestras capacidades ha llevado a que los usuarios tengan más tiempo del imaginado y con ello se ha visto mermada la inteligencia en general. Los usuarios no son capaces de resolver situaciones con recursos limitados, pues se han habituado a poder acceder y disponer de recursos para solventar el mínimo desliz.

Como bien señala Sherry Turkle (1996:304), "debe de haber algo que va mal con la realidad, si tantas personas quieren escapar de ella". Y más aún si el objetivo de estos usuarios es vivir físicamente en un mundo virtual. Liberarse del espacio real es una experiencia posible en la realidad virtual la cual rompe con el marco de la realidad cotidiana y que equivale a la posibilidad de que, en un futuro, las personas usen el ciberespacio para evadirse de sus cuerpos.

Por otro lado, la evolución de las relaciones analizadas anteriormente nos lleva por diferentes senderos de realidad virtual. Desde una virtualidad que persigue completar la realidad empobrecida; pasando por una simulación donde los humanos escapan de la realidad para adentrarse en la tecnología; para llegar a la conclusión que entre virtualidad y realidad no hay diferencia alguna pues lo real siempre ha sido virtual. Lo que el ojo humano ve son simulaciones de lo presente que el cerebro biológico descodifica. Asimismo, la realidad se constituye como nuestra identidad, a partir de la diferencia, característica que el mundo digital no posibilita pues los bits son los mismos para todos los elementos.

Debemos aunar aquí que las tecnologías han sido utilizadas por los usuarios como amplificadores de sus capacidades. Primero, para acortar el tiempo en el cortejo y en la creación de relaciones con otros usuarios ya sean del mismo sexo u opuesto. Posteriormente, para alcanzar una comunicación personal y profesional sin fronteras ni limitaciones físicas. Y, finalmente, la creación de un espacio y un ente inmortal. Sustituyendo elementos del cuerpo biológico e implantando otros para la prolongación de la existencia. Este fin tiene el peligro de devenir seres egocéntricos e impedir el desarrollo y creación de nuevas generaciones que aporten nuevas visiones y amplíen el desarrollo de la humanidad. 
Estamos siendo los protagonistas de nuestra futura destrucción al impedir el desarrollo evolutivo de la naturaleza.

Pronto las utopías y distopías representadas en nuestro cine y literatura dejarán de ser ciencia ficción y nuestra interacción desmaterializada habrá sucumbido a una superficialidad sin precedentes.

\section{Referencias}

BERNE, Eric. (1974) ¿Qué dice usted después de decir hola? Grijalbo Mondadori. Barcelona.

- (1983). Introducción al tratamiento de grupo. Grijalbo Mondadori. Barcelona.

BRIGGS, Asa. (2005). De Gutenberg a Internet. Una historia social de los medios de comunicación. Taurus. Madrid.

BURDEA, Grigore \& COIFFET, Philippe. (2004). Tecnologías de la realidad virtual. Paidós. Barcelona.

CÁCERES, María Dolores. (2003). Introducción a la comunicación interpersonal. Síntesis. Madrid.

CARD, Orson Scott. (2009). El juego de Ender (1985). Zeta Bolsillo, Barcelona.

CUESTA, Ubaldo. (2000). Psicología social de la comunicación. Cátedra, Madrid.

DIMURO PETER, Glenda. (2008). Los ecosistemas como laboratorio. La búsqueda de modos de vivir para una operatividad de la sostenibilidad. Universidad de Sevilla.

GIBSON, William. (2007). Neuromante (1984). Minotauro. Barcelona.

GIL VILLA, Fernando. (2001). Individualismo y cultura moral. Centro de investigaciones sociológicas. Madrid.

HORROCKS, Christopher. (2004). Marshall McLuhan y la realidad virtual. Gedisa. Barcelona.

HUXLEY, Aldoux. (2007). Un mundo feliz.

Debolsillo. Barcelona.

LÉVY, Pierre. (1999) ¿Qué es lo virtual? Paidós. Barcelona.
LIPOVETSKY, Gilles. (2009). La pantalla global. Cultura mediática y cine en la era hipermoderna. Anagrama. Barcelona.

MANOVICH, Lev. (2005). El lenguaje de los nuevos medios de comunicación. La imagen en la era digital. Paidós Comunicación. Barcelona.

MARTIN SERRANO, Manuel. (2007). Teoría de la comunicación. La comunicación, la vida y la sociedad. McGraw-Hill. Madrid.

MATTELART, Armand y Michèlle. (2005). Historia de las teorías de la comunicación. [Cap. 7 "La influencia de la comunicación”]. Paidós Ibérica, S.A.Barcelona.

MIRABITO, Michael M.A. (1998). Las nuevas tecnologías de la comunicación con contribuciones de Bárbara L. Morgenstern. Gedisa. Barcelona.

MUCCHIELLI, Alex. (1998). Psicología de la comunicación. Paidós Comunicación, Barcelona.

NEGROPONTE, Nicholas. (2000). El mundo digital. El futuro ha llegado. Biblioteca de bolsillo. Barcelona.

OPI, Juan Manuel. (2004). Las claves del

comportamiento humano. Conocerse y conocer a los demás. Amat, Barcelona D.L.

ORWELL, George. (2007). 1984. Destino, Barcelona.

PUYAL, Alfonso. (2006). Teoría de la comunicación audiovisual. Fragua. Madrid.

RHEINGOLD, Howard. (2002). Realidad virtual. Los mundos artificiales generados por ordenador que modificarán nuestras vidas. Colección límites de la ciencia. Volumen 24. Gedisa. Barcelona.

SÁNCHEZ NAVARRO, Jordi. (2004). Realidad virtual. Visiones sobre el ciberespacio. Devir S.L. Barcelona. 
SCOLARI, Carlos. (2008). Hipermediaciones. Elementos para una teoría de la comunicación digital interactiva. Gedisa. Barcelona.

SHANNON, Claude E. (1981). Teoría matemática de la comunicación. Forja. Madrid.

SMITH, Marc A. y KOLLOCK, Peter. (2003). Comunidades en el ciberespacio. UOC, Barcelona.

THOMPSON, John B. (2003). Los medios y la modernidad. Paidós comunicación. Barcelona.

TURKLE, Sherry. (1997). La vida en la pantalla. La construcción de la identidad en la era Internet. Paidós. Barcelona.

WATZLAWICK, Paul. (2006). Teoría de la comunicación humana: interacciones, patologías y paradojas. Herder, Barcelona D.L.

WILLIAMS, Raymond. (1992). Historia de la comunicación. Vol.2 De la imprenta a nuestros días. [Cap. 4 y 5]. Bosch Casa Editorial. Barcelona.

\section{Consultados por última vez el 15 de febrero de 2010.}

DAVIS, Richard. "Tecnologías de la comunicación y democracia: El factor Internet”. Dpto de ciencia política Brian Young University. UTA, USA.

Traducción de José Luis Dader.

[http: / / dialnet.unirioja.es/servlet/articulo?codigo $\equiv 646569$ ].

ESTALLO MARTI, Juan Alberto. "El impacto de las tecnologías de la información. Del PC a Internet".

Dpto de psicología junio 1997.

[http: / / www.ub.es/personal/impacto.htm].

GODOY ETCHEVERRY, Sergio. "Uso de Internet, medios de comunicación, expectativas políticas y generación de contenidos online. Resultados del proyecto WIP Chile 2003-2006". Conservatorio, 2008.

[http://www.obs.obercom.pt/index.php/obs/arti cle/viewPDFInterstitial/175/188].

INFOCOPOLINE. Revista de psicología. Félix Moral Toranzo. "Relaciones sociales en Internet". [http: / / www.infocoponline.es/view article.asp?id $=871$ ].

LIZARAZO ARIAS, Diego. "Paradojas de la sociedad cibernética”. Profesor - Investigador de la Universidad Autónoma Metropolitana, México. [http://www.diegolizarazo.com/pdfs/paradojas_d e la sociedad cibernetica.pdf]

\section{Cita de este artículo}

FELIPE AZNAR, V. (2010) La distopía de las relaciones interpersonales. Revista Icono14 [en línea] 1 de Julio de 2010, No Año 8, Vol. 2. pp. 118-135. Recuperado (Fecha de acceso), de http://www.icono14.net 


\section{NOTAS}

${ }^{i}$ William Gibson describió por primera vez en su novela Neuromante el concepto "ciberespacio" como "Una alucinación consensual experimentada diariamente por billones de legítimos operadores, en todas las naciones, por niños a quienes se enseña altos conceptos matemáticos... Una representación gráfica de la información abstraída de los bancos de todos los ordenadores del sistema humano. Una complejidad inimaginable. Líneas de luz dispuestas en el no-espacio de la mente, agrupaciones y constelaciones de datos..., el propio terreno de lo virtual, donde todos los medios se juntan (fluyen) y nos rodean".

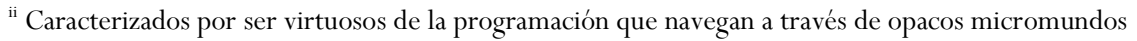
informáticos.

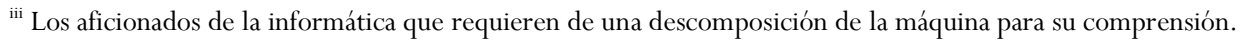
Estos no llegan a comprender el software, se quedan en lo superficial con una relación práctica con respecto al ordenador.

${ }^{\text {iv }}$ El origen está en el juego de rol Dragones y Mazmorras que triunfó en institutos y facultades a finales de los setenta y principio de los ochenta.

${ }^{v}$ IRC. Relay Chat en Internet (Charlas por relevos). Se trata de un foro vivo de conversaciones en conexión.

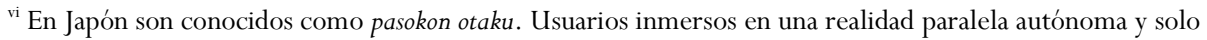
comprensible por ellos.

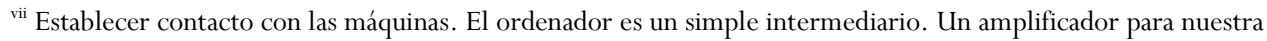
comunicación con otros usuarios. Mantenemos distancias y conservamos nuestra conciencia de ser seres humanos biológicos sin anhelos tecnológicos.

viii Entendamos como vía fría aquellas vías que no provengan de un ser humano. Se utiliza para su transmisión una tecnología.

${ }^{\text {ix }}$ La palabra "dildónica" fue acuñada en 1974 por el informático visionario Theodor Nelson (inventor del hipertexto y diseñador del software Xanadu), para describir una máquina inventada por un artesano de hardware de San Francisco, How Wachspress, un dispositivo capaz de convertir el sonido en sensaciones táctiles. El efecto erotógeno depende del sitio en que el consumidor decida hacer que su anatomía haga de interfaz con el estimulador táctil. La realidad virtual induce la posibilidad de una tecnología mucho más refinada.

${ }^{\mathrm{x}}$ Proviene del griego hápto (tocar). Estudia el tacto y sus sensaciones como medio de control e interacción de las personas con máquinas y ordenadores. Es un componente de la comunicación no verbal en las relaciones interpersonales y es vital para llegar a la intimidad física.

${ }^{x i}$ Se empezó a comercializar en 1987. Inventado por Thomas Zimmerman y respaldado por la NASA.

Posteriormente se le confió a VPL para que lo patentara (US Patent 4.542.291). (Grigori Burdea , 1996)

xii Dextrous Hand Master. Introducido en 1990 por Exos Inc. Consiste en una estructura metálica exosquelética que se lleva en el dorso de la mano. Lleva hasta 20 sensores. Tiene gran sensibilidad y una elevada resolución, pero requiere de una calibración antes de cada sesión y tiene problemas en cuanto a la precisión.

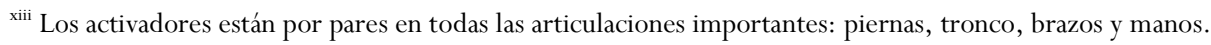
Desde la unidad de alimentación se distribuye aire comprimido de baja presión a los activadores de amplificación a través de una placa situada en la espalda. Las botas rebajan el centro de gravedad para mejorar la estabilidad y la distribución de las fuerzas. 
${ }^{\text {xiv }}$ Anglicismo propio de la jerga de Internet que hace alusión a la persona falta de habilidades técnicas. El término deriva de looser user y define a las personas que se aprovechan del trabajo de los demás en su beneficio y que presumen de las habilidades que no poseen.

${ }^{x v}$ ORWELL, George. (2006). 1984. Destino. Barcelona.

${ }^{\text {xvi }}$ En el mundo simulado hay tres grados dependiendo de la presencia humana en ellos. La simulación de vida, las personas reales usan equipos simulados en la vida real; la simulación virtual, las personas reales usan equipos simulados en mundos simulados; y la simulación constructiva, todo es una simulación -las personas simuladas usan equipos simulados en un mundo simulado-.

xvii Los cascos de simulación emplean diminutas pantallas ubicadas muy cerca de los ojos. Precisan unas ópticas especiales que permitan a los ojos enfocarse a muy poca distancia sin provocar cansancio. Hay cascos que emplean LCD con un campo de visión de $100^{\circ}$ en horizontal y $60^{\circ}$ en vertical con un peso considerable de 2,4 Kg. Por otro lado, los cascos CRT consisten en tubos catódicos miniaturizados incorporados en un casco ligero. Es mucho mejor que los LCD por su resolución y peso, además de contar con un sistema que elimina las interferencias electrónicas y disipa el calor lejos de la cabeza del usuario. (Grigori Burdea/ Philippe Coiffet, 1996:64)

xviii El patrón de organización es la configuración entre las relaciones de los componentes del sistema, determinando sus características esenciales. El elemento fundamental para el desarrollo de una nueva forma de pensar sea vivo o no. (Glenda Dimuro Peter, Los ecosistemas como laboratorios, 2008.)

${ }^{x i x}$ El Transhumanismo es tanto un concepto filosófico como un movimiento intelectual internacional que apoya el empleo de las nuevas ciencias y tecnologías para mejorar las capacidades mentales y físicas con el objeto de corregir lo que considera aspectos indeseables e innecesarios de la condición humana, como el sufrimiento, la enfermedad, el envejecimiento o incluso, en última instancia, la mortalidad. 